\title{
Optimal replenishment and pricing policies for deteriorating items with quadratic demand under trade credit, quantity discounts and cash discounts
}

\author{
Nita Shah ${ }^{\mathbf{a}^{*}}$ and Monika Naik ${ }^{\mathrm{a}}$ \\ ${ }^{a}$ Department of Mathematics, Gujarat University, India

\begin{tabular}{l} 
C H R O N I C L E \\
\hline Article history: \\
Received February 7, 2018 \\
Accepted December 62018 \\
Available online \\
December 62018 \\
\hline Keywords: \\
Trade credit \\
Quantity discounts \\
Cash discounts \\
Deteriorating items \\
Time-price dependent demand \\
rate
\end{tabular}

\section{Introduction}

In various inventory systems, the deterioration in products like fruits, vegetables, medicines etc. is normally observed, leading in excessive damages in quality as well as quantity of items. In order to raise the market demand many policies like trade credit, quantity discounts, cash discounts representing all forms of demand enhancing efforts. Many literature works on inventory control are demonstrated on the basis of assuming fixed rate of demand over entire inventory cycle. Even though, in real-life situations, there are many aspects affecting the rate of demand such as the price associated with selling of the items and the obtainability of items. On the basis of facts, the models dealing with inventory includes demand rates based on selling price of items are considered by decreasing price increases sales of many products.

The rate of market demand is assumed to fluctuate as a function, based on level of stock, the price value or together, in models on inventory with rates of demand as variable one. For deteriorating of items with the concept of partial back-logging and with a level of stock based rate of demand, and a bound on the extreme level of inventory, a model on inventory was represented by Min and Zhou (2009). Other model on inventory with rate of demand based on level of stock for items which are deteriorating in nature was proposed by Yang et al. (2010), permitting back-logging partially and including the

* Corresponding author

E-mail address: nitahshah@gmail.com (N. Shah)

C 2019 by the authors; licensee Growing Science, Canada doi: $10.5267 /$ j.uscm. 2018.12 .003 
inflation effect. An EOQ concept consisting of back-logging partially, in which the rate of demand is based on level of stock, and a manageable rate of deterioration determines the strategies of preservation and lot order size in optimum manner to rise the total profit to maximum, was formulated by Lee et. al. (2012).

Firstly, Silver et al. (1969) have attempted for time varying demand rate, then after many scholars named Silver (1979), Chung et al. (1993, 1994), Bose et al.(1995), Hariga (1995), Lin et al. (2000), Mehta et al. (2003, 2004), Shah et al. (2009), and Shah et al. (2014) have expressed rate of demand as time varying in terms of linear, exponential or quadratic, etc. in nature. Moreover, practically, to increase order quantity, supplier offers a trade credit to the retailer. From the retailer's view, granting trade credit not only increases sales and revenue but also increases opportunity cost. Initially, an inventory model with the permissible delay in payments was introduced by Haley and Higgins (1973). Kingsman (1983) highlighted the effects of various means of payment on stocking and ordering. An EOQ model was proposed by Goyal (1985) along with permissible delay in payments, with interest earned and paid. Aggarwal and Jaggi (1995) including deteriorating items modified Goyal's (1985) model. A Fuzzy EPQ model for deteriorating items was presented by Mahata and Goswami (2006) with allowable delay in payment. The concept of time-dependent demand and time-varying holding cost under partial backlogging was included in Mishra's et al. (2013) inventory model for deteriorating item. On the other hand, by expressing demand as a function of price and with considering the difference between the purchase cost and selling price, Teng et al. (2005) estimated the lot size and optimal price under allowable delay in payments. With the concept of permissible delay in payments, Shah and Shah (1998) proposed a probabilistic EOQ inventory model for deteriorating items considering demand is a random variable and time and deterioration of units as continuous variables. Lin et al. (2012) developed a united supplier-retailer inventory model with trade credit policy and allowing defective items by calculating optimal ordering and delivery policy. Many other significant articles related to trade credit such as Mahata and Goswami (2007), Arcelus et al. (2003), Jamal et al. (2000), Abad and Jaggi (2003), Chang (2004), Chung (2004) etc.

The listed above all inventory models assumes one-level trade credit. Nowadays, more and more efforts are drawn in raising the collective advantage by constructing coordinated model for both players rather than individual one in supply chain. According to the assumption, a delay period is offered by supplier to retailer, and within the trade credit period, the retailer could sell the goods and accumulate revenue and earn interest. But to enhance the customer's demand rate and to cutoff the on-hand stock cost, customer should also be offered a trade credit period by retailer. So, the supplier offers a credit period to the retailer and the retailer, offers the credit period to his/her customers. To stimulate the demand, Huang (2003) proposed an inventory model with an assumption that the retailer also permits a credit period to its customer which is shorter than the credit period offered by the supplier. Huang (2006) modified Huang (2003) model under two levels of trade credit and limited storage space to estimate the retailer's inventory policy. An inventory model for deteriorating items under two-level trade credit policy in fuzzy sense is proposed by Mahata and Goswami (2007) to determine an optimal ordering policy. Huang (2006) generalized Huang (2003) by developing an EPQ model to estimate the two-level trade credit policy. A fuzzy economic order quantity model for deteriorating items was proposed by Mahata and Mahata (2011) under retailer partial trade credit financing in a supply chain. An EPQ model was presented by Mahata (2012) for deteriorating items under retailer partial trade credit policy. Kreng and Tan (2010) altered Huang (2003) by presenting an EOQ model under two levels of trade credit policy depending on the order quantity by developing optimal wholesaler's replenishment decisions. A joint supplier buyer inventory model was proposed by Ho et al. (2008) with the assumption that demand is sensitive to retail price and the supplier adopts a two-part trade credit policy.

Hill and Riener (1979) constructed an inventory model to estimate the cash discount in the firm's cash credit policy, by including trade credit and firm's cash discount. An EOQ model with cash discount and trade credit is developed by Huang and Chung (2003). An optimal ordering policy was derived by 
Chang and Teng (2004) for a retailer with deteriorating item, in the case when supplier provides a cash discount as well as permissible delays to avoid default risks and to increase sales respectively. Dolan (1987) derived an inventory model including the concept of quantity discounts. Chung et al. (2017), proposed an inventory model with constant demand combining the concept of trade credit and quantity discounts. Another literature reviews on inventory modelling with trade credit and price discounts were demonstrated by Ouyang et al. (2005), Huang and Hsu (2007), Sana and Chaudhuri (2008), Ho et al. (2008), Yang (2010).

The main objective of this article is to maximize total profit by synchronizing various concepts like, two levels of trade credit, cash discount and quantity discount for deteriorating items with market demand depending on selling price and time and to construct a unique inventory model when the cash discount for the retailer depends on the ordering quantity and cash discount for the customer depends on the time when customer buys item. The variable demand comprising of combination of all above stated concepts for deteriorating products make this article a unique one. At last, to validate the derived models, numerical examples along with sensitivity analysis are undertaken, which extracts some fruitful managerial insights.

The organization of this article is consisting of the six sections stated as; section 2 represents the notations and assumptions. The model is introduced in section 3. Section 4, deals with the solution methodology adopted in this paper, also classical optimization technique is utilized to acquire the optimal policy. Section 5 consists of conducting numerical analysis and sensitivity analysis about the inventory parameters. Lastly, conclusion of the study is represented in section 6 .

\section{Notations and assumptions}

\subsection{Notations}

\begin{tabular}{ll}
\hline$D t(t, p)$ & Demand rate per unit at any time $t$ and at any price $p$ \\
A & Fixed ordering cost (Dollar/order) \\
$C$ & Unit purchasing price (in Dollars) \\
$h$ & Unit inventory holding cost/year excluding interest charges \\
$I_{e}$ & Annual interest earned (in Dollars) \\
$I_{c}$ & Annual interest charged (in Dollars) \\
$\theta$ & The constant deterioration rate \\
$M_{i}$ & $i^{t h}$ permissible delay period $(i=0,1,2)$ \\
$d_{1}$ & Cash discount rate offered by the supplier \\
$d_{2}$ & Cash discount rate offered by the retailer \\
$Q_{1}$ & The quantity at which the supplier provides the cash discount rate $d_{1}$ to the retailer
\end{tabular}

Decision variables

$\begin{array}{ll}T & \text { Replenishment cycle length } \\ p & \text { Unit selling price (in Dollars) } \\ T P(T, p) & \text { The total profit in each period (in Dollars) } \\ Q^{*} & \text { Optimum order size }\end{array}$

\subsection{Assumptions}

1. Infinite time horizon is considered.

2. Shortages are impermissible. 
3. Let the demand rate for the item be $D t(t, p)=a\left(1+b t-c t^{2}\right) p^{-\eta}$, a function of time; with $p$ as the selling price of customer per unit, where, $a>0$ is a scale demand, $0 \leq b<1$ denotes the linear rate of change of demand with respect to time, $0 \leq c<1$ denotes the quadratic rate of change of demand and $\eta$ is the mark up for selling price, where, $\eta>1$.

4. Instantaneous replenishments are considered.

5. $M_{0} \geq M_{1}>M_{2}$.

6. $0 \leq d_{1} \leq 1$.

7. $0 \leq d_{2} \leq 1$.

8. $\left(1-d_{2}\right) \cdot p \geq C$.

9. - The supplier offers a cash discount rate $d_{2}$ to the retailer for the ordering quantity $Q \geq Q_{1}$; and at time 0 , the retailer will settle the account and start paying for the interest charged on the items in stock with rate $I_{c}$.

- For the case, $Q<Q_{1}$ the retailer will have the trade credit period $M_{0}$. While the period when the account is not settled, the generated sales revenue is deposited in an interest-bearing account with the rate $I_{e}$. At the completion of this period, the account is settled and the retailer starts paying for the interest charged on the items in stock with rate $I_{c}$.

10. A customer gains a cash discount rate $d_{1}$ by retailer and makes payment at time period $t$ when the customer buys an item from the retailer at time $t \in\left[0, M_{2}\right]$. Moreover, a customer enjoys a trade credit period $M_{1}-t$ and makes the payment at time $M_{1}$, when the customer buys an item from the retailer at time $t \in\left(M_{2}, M_{1}\right]$.

11. For the utilization of other activities, the retailer retains the profit.

\section{Mathematical model formulation}

Let $[0, T]$ be the period of replenishment cycle where a firm tends to sell a single product, which is deteriorating in nature. The firm regulates the selling price $p$ with time period $t$ to fluctuate market demand $D t(p, t)$. Let the process of deterioration of product begins with the entry of the item in the system. The inventory deterioration is directly proportional to the level of inventory. ie. $\theta . I(t)$ For the period of scheduling horizon $[0, T]$, the level of inventory declines due to the collective influences of rate of market demand, and the inventory level at the end of replenishment cycle reaches zero. This inventory level scenario can be represented by the differential equation (1), with boundary condition, $I(T)=0$

$$
\frac{d I(t)}{d t}=-\theta I(t)-D t(p, t) \quad, 0 \leq t \leq T
$$

Equation (1) demonstrates that the level of inventory sustains non-negative nature for all time, i.e. for all $t \in[0, T], I(t) \geq 0$ without backordering throughout the scheduling horizon. On solving equation (1) with the boundary condition $I(T)=0$, the level of inventory at any time $t$ is demonstrated as in Eq. (2), 


$$
I(t)=\left\{\begin{array}{c}
-\frac{\left(p^{-\eta} a\right)\left(-c t^{2} \theta^{2}+b t \theta^{2}+2 c t \theta-b \theta+\theta^{2}-2 c\right)}{\theta^{3}} \\
+\frac{\left(p^{-\eta} a\right)\left(-c T^{2} \theta^{2}+b T \theta^{2}+2 c T \theta-b \theta+\theta^{2}-2 c\right)\left(e^{\theta(T-t)}\right)}{\theta^{3}}
\end{array}\right\}
$$

The optimal ordered quantity is derived as stated below:

$$
Q^{*}=I(0)=\left\{\begin{array}{c}
-\frac{\left(p^{-\eta} a\right)\left(-b \theta+\theta^{2}-2 c\right)}{\theta^{3}} \\
+\frac{\left(p^{-\eta} a\right)\left(-c T^{2} \theta^{2}+b T \theta^{2}+2 c T \theta-b \theta+\theta^{2}-2 c\right)\left(e^{\theta T}\right)}{\theta^{3}}
\end{array}\right\}
$$

$$
\text { Let } \frac{Q_{1}}{\int_{0}^{T} D t(p, t) d t}=t_{1} \text {. }
$$

There are following four cases that occurs in this inventory problem:

1. $0 \leq M_{2}<M_{1} \leq M_{0}<\frac{Q_{1}}{\int_{0}^{T} D t d t}$;

2. $0<M_{2}<M_{1}<\frac{Q_{1}}{\int_{0}^{T} D t d t} \leq M_{0}$;

3. $0<M_{2}<\frac{Q_{1}}{\int_{0}^{T} D t d t} \leq M_{1}<M_{0}$;

4. $0<\frac{Q_{1}}{\int_{0}^{T} D t d t} \leq M_{2}<M_{1} \leq M_{0}$.

Case 1. $0 \leq M_{2}<M_{1} \leq M_{0}<\frac{Q_{1}}{\int_{0}^{T} D t d t}$

The total profit of the system is computed with the following components:

1. Sales revenue: The sales revenue per unit time is given by,

$$
S R=\frac{(p-C) \int_{0}^{T} D t(p, t) d t}{T}=\int_{0}^{T} \frac{(p-C)\left[a\left(1+b t-c t^{2}\right) p^{-\eta}\right] d t}{T}
$$

2. Holding cost: Suppose with the positive holding cost co-efficient $h$, the holding cost function per unit time is given by,

$$
H C=\frac{h \cdot \int_{0}^{T} I(t) d t}{T}=\frac{h \cdot \int_{0}^{T}\left\{\begin{array}{c}
-\frac{\left(p^{-\eta} a\right)\left(-c t^{2} \theta^{2}+b t \theta^{2}+2 c t \theta-b \theta+\theta^{2}-2 c\right)}{\theta^{3}} \\
\left.+\frac{\left(p^{-\eta} a\right)\left(-c T^{2} \theta^{2}+b T \theta^{2}+2 c T \theta-b \theta+\theta^{2}-2 c\right)\left(e^{\theta(T-t)}\right)}{\theta^{3}}\right\} d t
\end{array}\right]}{T}
$$

3. Ordering cost: The ordering cost per unit time, with $A$, as order cost per order is given by,

$$
O C=\frac{A}{T}
$$


4. Purchasing cost: The purchasing cost with $C$ as cost of purchasing per unit item per year and cost of interest charges for the items kept in stock is stated as,

1. $\frac{Q_{1}}{\int_{0}^{T} D t d t} \leq T$

In this situation, the ordering quantity, $Q_{1} \leq T \cdot \int_{0}^{T} D t d t=Q \Rightarrow Q_{1} \leq Q$ the supplier will offer a cash discount with rate $d_{1}$ to the retailer. Also, by assumption 11, the retailer retains the profit for the use of other activities. Therefore, the retailer will gradually settles the account with $\frac{C}{T} \int_{0}^{\left(1-d_{1}\right) \cdot T} t . D t d t$ per unit time from the generated sales revenue at time zero and completely settle down the account at time $\left(1-d_{1}\right) . T$. Also, the payment of interest charges on the items in stock with rate $I_{c}$ is started by the retailer at time 0 and ends at time period $\left(1-d_{1}\right) \cdot T$. Therefore, the purchasing cost and interest charged per year is calculated as,

$$
\begin{aligned}
& P C_{1}=\frac{C}{T} \int_{0}^{\left(1-d_{1}\right) \cdot T} t \cdot D t d t \\
& I C C_{1}=\frac{C \cdot I_{C}}{T} \int_{0}^{\left(1-d_{1}\right) \cdot T} D t .(T-t) d t
\end{aligned}
$$

2. $M_{0} \leq T<\frac{Q_{1}}{\int_{0}^{T} D t d t}$.

In this situation, the ordering quantity $Q=T \cdot \int_{0}^{T} D t d t<Q_{1} \Rightarrow Q<Q_{1}$; as per assumption-9, the retailer will have the trade credit period $M_{0}$. Therefore, the purchasing cost per year and interest earned per year can be calculated as,

$$
\begin{aligned}
P C_{2} & =\frac{C \cdot \int_{0}^{T} t \cdot D t d t}{T} \\
I C C_{2} & =\frac{C \cdot I_{C}}{T} \int_{0}^{\left(T-M_{0}\right)} D t \cdot(T-t) d t
\end{aligned}
$$

3. $M_{1} \leq T<M_{0}<\frac{Q_{1}}{\int_{0}^{T} D t d t}$

In this situation, the ordering quantity $Q=T \cdot \int_{0}^{T} D t d t<Q_{1} \Rightarrow Q<Q_{1}$; as per assumption 9, the retailer will have the trade credit period $M_{0}$. As, $T<M_{0}$ the purchasing cost per year and interest earned per year can be calculated as,

$$
\begin{aligned}
& P C_{3}=\frac{C \cdot \int_{0}^{T} t \cdot D t d t}{T} \\
& I C C_{3}=0
\end{aligned}
$$

4. $0<M_{2} \leq T<M_{1} \leq M_{0}<\frac{Q_{1}}{\int_{0}^{T} D t d t}$

In this situation, as in case-3, the ordering quantity $Q=T \cdot \int_{0}^{T} D t d t<Q_{1} \Rightarrow Q<Q_{1}$; as per assumption 9, the retailer will have the trade credit period $M_{0}$. As, $T<M_{0}$ the purchasing cost per year and interest earned per year can be calculated as, 


$$
\begin{aligned}
& P C_{4}=\frac{C \cdot \int_{0}^{T} t \cdot D t d t}{T} \\
& I C C_{4}=0
\end{aligned}
$$

5. $0<T<M_{2}<M_{1} \leq M_{0}<\frac{Q_{1}}{\int_{0}^{T} D t d t}$

In this situation also, as in case-3, the ordering quantity $Q=T \cdot \int_{0}^{T} D t d t<Q_{1} \Rightarrow Q<Q_{1}$; as per assumption 9, the retailer will have the trade credit period $M_{0}$. As, $T<M_{0}$ the purchasing cost per year and interest earned per year can be calculated as,

$$
\begin{aligned}
& P C_{5}=\frac{C \cdot \int_{0}^{T} t \cdot D t d t}{T} \\
& I C C_{5}=0
\end{aligned}
$$

5. Interest earned throughout the permissible payment period.

1. $\frac{Q_{1}}{\int_{0}^{T} D t d t} \leq T$

In this situation, the ordering quantity $Q_{1} \leq T \cdot \int_{0}^{T} D t d t=Q \Rightarrow Q_{1} \leq Q$.As per assumption-9, the retailer enjoys a cash discount offered by the supplier with rate $d_{1}$. The retailer will slowly settles the account during the period $\left[0,\left(1-d_{1}\right) \cdot T\right]$. Also, the retailer begins to pay interest charges for the time period starting with 0 to time period $\left(1-d_{1}\right) . T$ and by assumption 11 , the retailer retains the profit for the use of other activities. Therefore, the interest earned per year is calculated as,

$$
I E_{1}=0
$$

2. $M_{0} \leq T<\frac{Q_{1}}{\int_{0}^{T} D t d t}$

In this situation, the ordering quantity is $Q=T \cdot \int_{0}^{T} D t d t \leq Q_{1} \Rightarrow Q \leq Q_{1}$.

As per assumption-9, the retailer enjoys trade credit period $M_{0}$. Moreover, as per assumption 11, there exist four cases:

1.1 Suppose a customer purchases a product from the retailer at time period $t \in\left[0, M_{2}\right]$ then the customer gains a cash discount offered by the retailer with rate $d_{2}$; and make the payment at time $t$. Thus, in such scenario, the interest earned per year is given by,

$$
I E_{21}=\frac{p \cdot I_{e}}{T}\left[\int_{0}^{M_{2}} t \cdot D t d t\right]
$$

2.2 Suppose a customer purchases a product from the retailer at time period $t \in\left[M_{2}, M_{1}\right)$ then the customer gains a trade credit period $M_{1}-t$ does payment at time period $M_{1}$. Therefore, during the time period $\left[M_{2}, M_{1}\right)$ the retailer will have on hand cash $\left(1-d_{2}\right) \cdot p \cdot I_{e} \int_{0}^{M_{2}} t \cdot D t d t$. Thus, in such scenario, the interest earned per year is given by,

$$
I E_{22}=\left(1-d_{2}\right) \cdot p \cdot I_{e} \cdot\left(M_{1}-M_{2}\right) \int_{0}^{M_{2}} t \cdot D t d t
$$


2.3 Suppose a customer purchases a product from the retailer at time period $t \in\left[M_{1}, M_{0}\right)$

Then the customer have to make the payment instantly. Since each customer purchases the product from the retailer at time period $t \in\left[M_{2}, M_{1}\right)$, they have to complete the payment at time $M_{1}$.Therefore, during the time period $\left[M_{1}, M_{0}\right)$ the retailer will have on hand cash $\left(1-d_{2}\right) \cdot p \cdot \int_{0}^{M_{2}} t \cdot D t d t+p \cdot \int_{M_{2}}^{\left(M_{1}-M_{2}\right)} t \cdot D t d t \quad$ at $\quad$ time period $\quad M_{1}$ and $\left(1-d_{2}\right) \cdot p \cdot \int_{0}^{M_{2}} t \cdot D t d t+p \cdot \int_{M_{2}}^{\left(M_{0}-M_{2}\right)} t \cdot D t d t$ at time $M_{0}$. Thus, in such scenario, the interest earned per year is given by,

$$
I E_{23}=\left\{\begin{array}{l}
\left(1-d_{2}\right) \cdot p \cdot \int_{0}^{M_{2}} t \cdot D t d t+p \cdot \int_{M_{2}}^{\left(M_{1}-M_{2}\right)} t \cdot D t d t \\
+\left(1-d_{2}\right) \cdot p \cdot \int_{0}^{M_{2}} t \cdot D t d t+p \cdot \int_{M_{2}}^{\left(M_{0}-M_{2}\right)} t \cdot D t d t
\end{array}\right\} \cdot \frac{\left(M_{0}-M_{1}\right) \cdot I_{e}}{T}
$$

Suppose a customer purchases a product from the retailer at time period $t \in\left[M_{0}, T\right]$

and the payment is done up to $M_{0}$. Then as per assumption 11, the retailer retains the profit for the utilization of other activities. Thus, in such scenario, the interest earned per year is given by,

$$
I E_{24}=0
$$

Therefore, on combining equations (18) to equation (21), the aggregated interest earned per year can be calculated as,

$$
\begin{gathered}
I E_{2}=I E_{21}+I E_{22}+I E_{23}+I E_{24} \\
I E_{2}=\left\{\begin{aligned}
\frac{p \cdot I_{e}}{T}\left[\int_{0}^{M_{2}} t \cdot D t d t\right]+\left(1-d_{2}\right) \cdot p \cdot I_{e} \cdot\left(M_{1}-M_{2}\right) \int_{0}^{M_{2}} t \cdot D t d t \\
+\left\{\begin{array}{l}
\left(1-d_{2}\right) \cdot p \cdot \int_{0}^{M_{2}} t \cdot D t d t+p \cdot \int_{M_{2}}^{\left(M_{1}-M_{2}\right)} t \cdot D t d t \\
+\left(1-d_{2}\right) \cdot p \cdot \int_{0}^{M_{2}} t \cdot D t d t+p \cdot \int_{M_{2}}^{\left(M_{0}-M_{2}\right)} t \cdot D t d t
\end{array}\right\} \cdot \frac{\left(M_{0}-M_{1}\right) \cdot I_{e}}{T}
\end{aligned}\right.
\end{gathered}
$$

3. $M_{1} \leq T<M_{0}<\frac{Q_{1}}{\int_{0}^{T} D t d t}$

In this situation, apply the same techniques of arguments as in 'case-2. By using assumptions 9 and 10 , the interest earned per year can be calculated as,

$$
I E_{3}=\left\{\begin{array}{l}
\frac{\left(1-d_{2}\right) \cdot p \cdot I_{e}}{T} \int_{0}^{M_{2}} t \cdot D t d t+\frac{\left(1-d_{2}\right) \cdot p \cdot I_{e} \cdot\left(M_{1}-M_{2}\right)}{T} \int_{0}^{M_{2}} t \cdot D t d t \\
+\left[\begin{array}{l}
\left\{\left(1-d_{2}\right) \cdot \int_{0}^{M_{2}} t \cdot D t d t+\int_{M_{2}}^{\left(M_{1}-M_{2}\right)} t \cdot D t d t\right\} \\
+\left\{\left(1-d_{2}\right) \cdot \int_{0}^{M_{2}} t \cdot D t d t+\int_{M_{2}}^{\left(T-M_{2}\right)} t \cdot D t d t\right\}
\end{array}\right] \cdot \frac{p \cdot\left(T-M_{1}\right) \cdot I_{e}}{T} \\
+\left[\left(1-d_{2}\right) \cdot \int_{0}^{M_{2}} t \cdot D t d t+\int_{M_{2}}^{\left(T-M_{2}\right)} t \cdot D t d t\right] \cdot \frac{p \cdot\left(M_{0}-T\right) \cdot I_{e}}{T}
\end{array}\right\}
$$

4. $0<M_{2} \leq T<M_{1} \leq M_{0}<\frac{Q_{1}}{\int_{0}^{T} D t d t}$

In this situation, apply the same techniques of arguments as in case-2. By using assumptions 9 and 10 , the interest earned per year can be calculated as, 


$$
I E_{4}=\left\{\begin{array}{l}
\frac{\left(1-d_{2}\right) \cdot p \cdot I_{e}}{T} \int_{0}^{M_{2}} t \cdot D t d t+\frac{\left(1-d_{2}\right) \cdot p \cdot I_{e} \cdot\left(M_{1}-M_{2}\right)}{T} \int_{0}^{M_{2}} t \cdot D t d t \\
+\left[\left(1-d_{2}\right) \cdot \int_{0}^{M_{2}} t \cdot D t d t+\int_{M_{2}}^{\left(T-M_{2}\right)} t \cdot D t d t\right] \cdot \frac{p \cdot\left(M_{0}-M_{1}\right) \cdot I_{e}}{T}
\end{array}\right\}
$$

5. $0<T<M_{2}<M_{1} \leq M_{0}<\frac{Q_{1}}{\int_{0}^{T} D t d t}$

In this situation, apply the same techniques of arguments as in case-2. By using assumptions 9 and 10 , the interest earned per year can be calculated as,

$$
I E_{5}=\left\{\frac{\left(1-d_{2}\right) \cdot p \cdot I_{e}}{T} \int_{0}^{T} t \cdot D t d t+\frac{\left(1-d_{2}\right) \cdot p \cdot I_{e}}{T} \int_{T}^{\left(M_{0}-T\right)} t \cdot D t d t\right\}
$$

Therefore, the total profit of inventory system per unit time is calculated by subtracting the applicable costs from the sales revenue, denoted by $T P(p, T)$ and computed as,

$$
T P(p, T)=\left\{\begin{array}{lc}
T P_{1}, & 0<T<M_{2} \\
T P_{2}, & M_{2} \leq T<M_{1} \\
T P_{3}, & M_{1} \leq T<M_{0} \\
T P_{4}, & M_{0} \leq T<\frac{Q_{1}}{\int_{0}^{T} D t d t} \\
T P_{5}, & \frac{Q_{1}}{\int_{0}^{T} D t d t} \leq T
\end{array}\right.
$$

where, $T P_{i}(p, T)=\left\{\begin{array}{l}\text { Sales revenue-Holding cost - Purchasing cost-Ordering cost } \\ \text {-Interest charged }+ \text { Interest earned }\end{array}\right\}$ i.e. $T P_{1}=S R-O C-H C-P C_{5}-I C C_{5}+I E_{5}$

$$
\left.\begin{array}{c}
\left.T P_{1}=\left\{\begin{array}{c}
h \cdot \int_{0}^{T}\left\{\begin{array}{l}
-\frac{\left(p^{-\eta} a\right)\left(-c t^{2} \theta^{2}+b t \theta^{2}+2 c t \theta-b \theta+\theta^{2}-2 c\right)}{\theta^{3}} \\
\frac{(p-C) \int_{0}^{T} D t(p, t) d t}{T}
\end{array}\right]+\frac{A}{T}-\frac{\left(p^{-\eta} a\right)\left(\begin{array}{l}
-c T^{2} \theta^{2}+b T \theta^{2} \\
+2 c T \theta-b \theta \\
+\theta^{2}-2 c
\end{array}\right)\left(e^{\theta(T-t)}\right)}{\theta^{3}} \\
T
\end{array}\right\} d t\right\} \\
-\frac{C \cdot \int_{0}^{T} t \cdot D t d t}{T}+\left\{\frac{\left(1-d_{2}\right) \cdot p \cdot I_{e}}{T} \int_{0}^{T} t \cdot D t d t+\frac{\left(1-d_{2}\right) \cdot p \cdot I_{e}}{T} \int_{T}^{\left(M_{0}-T\right)} t \cdot D t d t\right\} \\
T P_{2}=S R-O C-H C-P C_{4}-I C C_{4}+I E_{4}
\end{array}\right\}
$$




$$
\left.\begin{array}{c}
T P_{2}=\left\{\begin{array}{c}
\left.h \cdot \int_{0}^{T}\left\{\begin{array}{c}
-\frac{\left(p^{-\eta} a\right)\left(-c t^{2} \theta^{2}+b t \theta^{2}+2 c t \theta-b \theta+\theta^{2}-2 c\right)}{\theta^{3}} \\
(p-C) \int_{0}^{T} D t(p, t) d t \\
T
\end{array}\right\} \begin{array}{c}
\left(p^{-\eta} a\right)\left(\begin{array}{l}
-c T^{2} \theta^{2}+b T \theta^{2} \\
+2 c T \theta-b \theta \\
+\theta^{2}-2 c
\end{array}\right)\left(e^{\theta(T-t)}\right) \\
+\frac{A}{T}-\frac{T}{T}
\end{array}\right\} d t \\
-\frac{C \cdot \int_{0}^{T} t \cdot D t d t}{T}+\left\{\begin{array}{l}
\frac{\left(1-d_{2}\right) \cdot p \cdot I_{e}}{T} \int_{0}^{M_{2}} t \cdot D t d t+\frac{\left(1-d_{2}\right) \cdot p \cdot I_{e} \cdot\left(M_{1}-M_{2}\right)}{T} \int_{0}^{M_{2}} t \cdot D t d t \\
+\left[\left(1-d_{2}\right) \cdot \int_{0}^{M_{2}} t \cdot D t d t+\int_{M_{2}}^{\left(T-M_{2}\right)} t \cdot D t d t\right] \cdot \frac{p \cdot\left(M_{0}-M_{1}\right) \cdot I_{e}}{T}
\end{array}\right\}
\end{array}\right. \\
T P_{3}=S R-O C-H C-P C_{3}-I C C_{3}+I E_{3}
\end{array}\right\}
$$

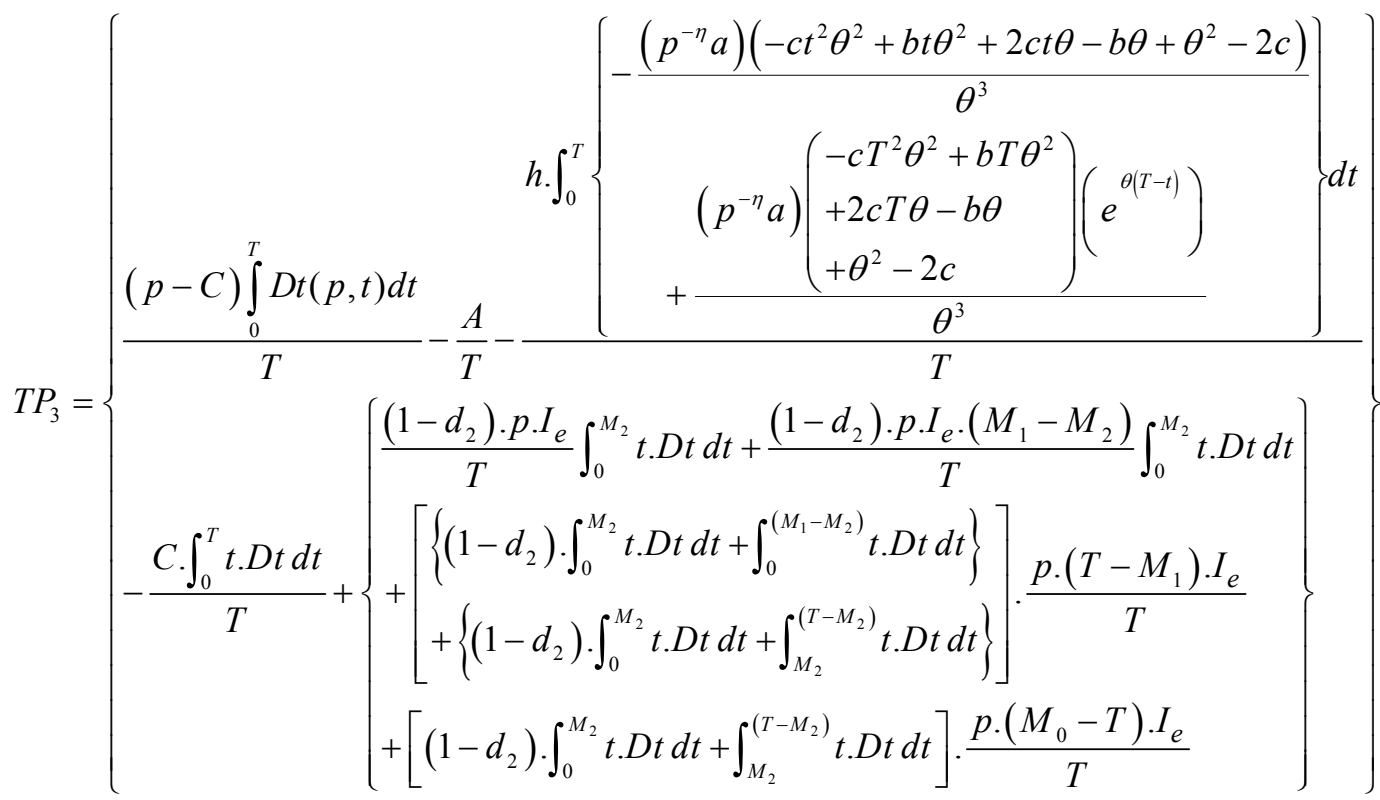

$$
T P_{4}=S R-O C-H C-P C_{2}-I C C_{2}+I E_{2}
$$

$$
T P_{4}=\left\{\begin{array}{l}
\left.\frac{h \cdot \int_{0}^{T}\left\{\begin{array}{l}
-\frac{\left(p^{-\eta} a\right)\left(-c t^{2} \theta^{2}+b t \theta^{2}+2 c t \theta-b \theta+\theta^{2}-2 c\right)}{\theta^{3}} \\
(p-C) \int_{0}^{T} D t(p, t) d t \\
T
\end{array}-\frac{A}{T}-\frac{\left(p^{-\eta} a\right)\left(\begin{array}{l}
-c T^{2} \theta^{2}+b T \theta^{2} \\
+2 c T \theta-b \theta+\theta^{2}-2 c
\end{array}\right)\left(e^{\theta(T-t)}\right)}{\theta^{3}}\right.}{T}\right\} d t \\
-\frac{C \cdot \int_{0}^{T} t \cdot D t d t}{T}-\frac{C \cdot I_{c}}{T} \int_{0}^{\left(T-M_{0}\right)} D t \cdot(T-t) d t \\
+\left\{\begin{array}{l}
\frac{p \cdot I_{e}}{T}\left[\int_{0}^{M_{2}} t \cdot D t d t\right]+\left(1-d_{2}\right) \cdot p \cdot I_{e} \cdot\left(M_{1}-M_{2}\right) \int_{0}^{M_{2}} t \cdot D t d t \\
\left(1-d_{2}\right) \cdot p \cdot \int_{0}^{M_{2}} t \cdot D t d t+p \cdot \int_{M_{2}}^{\left(M_{1}-M_{2}\right)} t \cdot D t d t \\
+\left\{\left(1-d_{2}\right) \cdot p \cdot \int_{0}^{M_{2}} t \cdot D t d t+p \cdot \int_{M_{2}}^{\left(M_{0}-M_{2}\right)} t \cdot D t d t\right.
\end{array}\right\} \cdot \frac{\left(M_{0}-M_{1}\right) \cdot I_{e}}{T}
\end{array}\right\}
$$




$$
\begin{aligned}
& T P_{5}=S R-O C-H C-P C_{1}-I C C_{1}+I E_{1} \\
& T P_{5}=\left\{\begin{array}{l}
h \cdot \int_{0}^{T}\left\{\begin{array}{l}
-\frac{\left(p^{-\eta} a\right)\left(-c t^{2} \theta^{2}+b t \theta^{2}+2 c t \theta-b \theta+\theta^{2}-2 c\right)}{\theta^{3}} \\
\frac{(p-C) \int_{0}^{T} D t(p, t) d t}{T}-\frac{A}{T}-\frac{\left(p^{-\eta} a\right)\left(\begin{array}{l}
-c T^{2} \theta^{2}+b T \theta^{2} \\
+2 c T \theta-b \theta+\theta^{2}-2 c
\end{array}\right)\left(e^{\theta(T-t)}\right)}{\theta^{3}}
\end{array}\right\} d t \\
-\frac{C}{T} \int_{0}^{\left(1-d_{1}\right) \cdot T} t \cdot D t d t-\frac{C \cdot I_{c}}{T} \int_{0}^{\left(1-d_{1}\right) \cdot T} D t \cdot(T-t) d t
\end{array}\right\}
\end{aligned}
$$

Applying the analogous techniques of arguments as demonstrated in Case-1., the total profit for all the Cases 2. - Case-4 can be described as shown below:

Case-2. $0<M_{2}<M_{1}<\frac{Q_{1}}{\int_{0}^{T} D t d t} \leq M_{0}$;

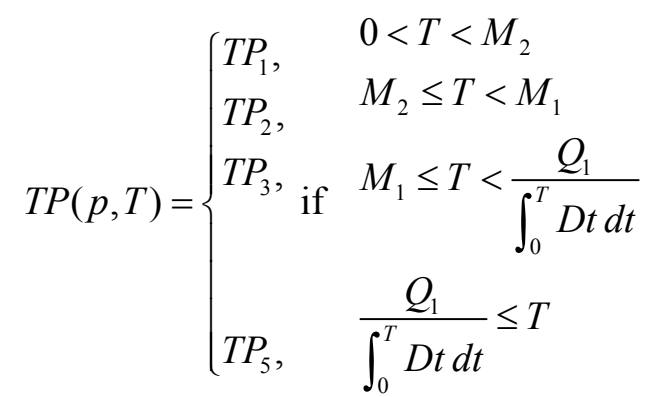

Case-3: $0<M_{2}<\frac{Q_{1}}{\int_{0}^{T} D t d t} \leq M_{1}<M_{0}$;

$$
T P(p, T)=\left\{\begin{array}{lcc}
T P_{1}, & 0<T<M_{2} \\
T P_{2}, & \text { if } & M_{2} \leq T<M_{1} \\
& \frac{Q_{1}}{T_{5},} & \int_{0}^{T} D t d t
\end{array}\right.
$$

Case-4: $0<\frac{Q_{1}}{\int_{0}^{T} D t d t} \leq M_{2}<M_{1} \leq M_{0}$.

$$
T P(p, T)=\left\{\begin{array}{lcc}
T P_{1}, & & 0<T<\frac{Q_{1}}{\int_{0}^{T} D t d t} \\
& \text { if } & \frac{Q_{1}}{T_{5},} \\
\int_{0}^{T} D t d t &
\end{array}\right.
$$

As it is difficult to prove analytically, so we prefer numerical and graphical solution which helps to show the concavity of the total profit function. For computing the decision variable and the total profit function, we utilize mathematical software Maple XVIII which gives the local solution.

Now, to maximize the average total profit stated in equation (26), we apply the below stated necessary and sufficient condition:

Assuming, 


$$
\frac{\partial T P}{\partial T}=0, \frac{\partial T P}{\partial p}=0
$$

To check the concavity of the total profit function of obtained solution, we adopt the below stated algorithm,

Step 1: Assigning the inventory parameters some specific hypothetical values.

Step 2: Obtaining the solutions by solving simultaneous equations stated in equation (35), utilizing the mathematical software Maple XVIII.

Step 3: Computing all the Eigen values of below stated hessian matrix $H$ at the optimal point obtained from equation (35),

$$
H=\left[\begin{array}{ll}
\frac{\partial^{2} T P}{\partial T^{2}} & \frac{\partial^{2} T P}{\partial T p} \\
\frac{\partial^{2} T P}{\partial p T} & \frac{\partial^{2} T P}{\partial p^{2}}
\end{array}\right]
$$

- If all of the eigenvalues are negative, it is said to be a negative-definite matrix. Then the profit function is concave down, which demonstrates the local maximum of the total profit function.

Then, on satisfying the above condition for the obtained values, we can say the total profit function is concave and then stop.

\section{Numerical example and sensitivity analysis}

In this section, we provide numerical examples to illustrate the various mathematical models derived above.

Example 1. Assume the following values in developed model.

$$
\begin{aligned}
& a=50000 \text { units }, b=30 \%, c=6 \%, h=\$ 0.1 / \text { unit }, C=\$ 20 / \text { unit }, d_{1}=30 \%, \\
& d_{2}=85 \%, A=\$ 100 / \text { unit }, \theta=1 \%, I_{c}=50 \%, I_{e}=10 \%, \eta=1.037, \\
& Q_{1}=10 \text { units, } M_{0}=0.85 \approx 310 \text { days, } M_{1}=0.8 \approx 292 \text { days, } M_{2}=0.7 \approx 255 \text { days. }
\end{aligned}
$$

Solution: $\quad$ As $Q=T \cdot \int_{0}^{T} D t d t \approx 2$ units ; Therefore, $Q=2$ units $<Q_{1}=10$ units

The optimal cycle time is $T=0.1681 \approx 61$ days; The optimal Selling price $p=\$ 594.7506$;

$\frac{Q_{1}}{\int_{0}^{T} D t d t}=0.8747 \approx 319$ days; By using case -1 , as $0<T<M_{2}<M_{1}<M_{0}<\frac{Q_{1}}{\int_{0}^{T} D t d t}$;

The total profit per year TP $=\$ 39296.1$; The optimal order quantity $Q^{*}=11$ units.

Example 2. Assume the following values in developed model.

$$
\begin{aligned}
& a=50000 \text { units }, b=15 \%, c=72 \%, h=\$ 0.1 / \text { unit }, C=\$ 20 / \text { unit }, d_{1}=20 \%, \\
& d_{2}=80 \%, A=\$ 100 / \text { unit }, \theta=15 \%, I_{c}=50 \%, I_{e}=10 \%, \eta=1.03, \\
& Q_{1}=10 \text { units, } M_{0}=0.85 \approx 310 \text { days, } M_{1}=0.8 \approx 292 \text { days }, M_{2}=0.2 \approx 73 \text { days. }
\end{aligned}
$$

Solution: $\quad$ As $Q=T \cdot \int_{0}^{T} D t d t \approx 2$ units ; Therefore, $Q=2$ units $<Q_{1}=10$ units 
The optimal cycle time is $T=0.2128 \approx 77$ days; The optimal Selling price $p=\$ 754.9040$;

$\frac{Q_{1}}{\int_{0}^{T} D t d t}=0.8607 \approx 314$ days. By using case -2 , as $0<M_{2} \leq T<M_{1} \leq M_{0}<\frac{Q_{1}}{\int_{0}^{T} D t d t}$;

The total profit per year $\mathrm{TP}=\$ 39801.1867$; The optimal order quantity $\mathrm{Q}^{*}=11$ units.

Example 3. Assume the following values in developed model.

$$
\begin{aligned}
& a=50000 \text { units }, b=26 \%, c=90 \%, h=\$ 0.01 / \text { unit }, C=\$ 20 / \text { unit }, d_{1}=20 \%, \\
& d_{2}=60 \%, A=\$ 100 / \text { unit }, \theta=10 \%, I_{c}=60 \%, I_{e}=10 \%, \eta=1.03, \\
& Q_{1}=10 \text { units, } M_{0}=0.6 \approx 219 \text { days, } M_{1}=0.2 \approx 73 \text { days, } M_{2}=0.1 \approx 36 \text { days. }
\end{aligned}
$$

Solution: $\quad$ As $Q=T \cdot \int_{0}^{T} D t d t \approx 4$ units ; Therefore, $Q=4$ units $<Q_{1}=10$ units

The optimal cycle time is $T=0.2779 \approx 101$ days. The optimal Selling price $p=\$ 780.0812$;

$\frac{Q_{1}}{\int_{0}^{T} D t d t}=0.6766 \approx 246$ days. By using case -3 , as $M_{1} \leq T<M_{0}<\frac{Q_{1}}{\int_{0}^{T} D t d t} ;$

The total profit per year $\mathrm{TP}=\$ 40016.9950$; The optimal order quantity $\mathrm{Q}^{*}=14$ units.

Example 4. Assume the following values in developed model.

$$
\begin{aligned}
& a=50000 \text { units }, b=45 \%, c=99.9 \%, h=\$ 0.01 / \text { unit }, C=\$ 20 / \text { unit }, d_{1}=20 \%, \\
& d_{2}=60 \%, A=\$ 100 / \text { unit }, \theta=10 \%, I_{c}=60 \%, I_{e}=10 \%, \eta=1.14, \\
& Q_{1}=10 \text { units, } M_{0}=0.2 \approx 73 \text { days }, M_{1}=0.1 \approx 36 \text { days, } M_{2}=0.06 \approx 21 \text { days. }
\end{aligned}
$$

Solution: $\operatorname{As} Q=T \cdot \int_{0}^{T} D t d t \approx 8$ units; Therefore, $Q=8$ units $<Q_{1}=10$ units

The optimal cycle time is $T=0.2555 \approx 93$ days; The optimal Selling price $p=\$ 188.3776$;

$\frac{Q_{1}}{\int_{0}^{T} D t d t}=0.2963 \approx 108$ days; By using case -4 , as $M_{0} \leq T<\frac{Q_{1}}{\int_{0}^{T} D t d t} ;$

The total profit per year TP $=\$ 21449.3932$; The optimal order quantity $Q^{*}=34$ units.

Example 5. Assume the following values in developed model.

$$
\begin{aligned}
& a=50000 \text { units }, b=99.9 \%, c=99.9 \%, h=\$ 0.01 / \text { unit }, C=\$ 20 / \text { unit }, d_{1}=20 \%, \\
& d_{2}=60 \%, A=\$ 100 / \text { unit }, \theta=10 \%, I_{c}=60 \%, I_{e}=10 \%, \eta=1.03, \\
& Q_{1}=10 \text { units, } M_{0}=0.2 \approx 73 \text { days, } M_{1}=0.1 \approx 36 \text { days, } M_{2}=0.06 \approx 21 \text { days. }
\end{aligned}
$$

Solution: $\quad \operatorname{As} Q=T \cdot \int_{0}^{T} D t d t \approx 26$ units ; Therefore, $Q=26$ units $>Q_{1}=10$ units

The optimal cycle time is $T=0.7335 \approx 267$ days; The optimal Selling price $p=\$ 992.999$;

$\frac{Q_{1}}{\int_{0}^{T} D t d t}=0.2804 \approx 102$ days.By using case -5 , as $\frac{Q_{1}}{\int_{0}^{T} D t d t} \leq T$;

The total profit per year $\mathrm{TP}=\$ 46718.7517$; The optimal order quantity $\mathrm{Q}^{*}=37$ units. 
As, the total profit is maximum in case- $5 ; \frac{Q_{1}}{\int_{0}^{T} D t d t} \leq T$, So, by using algorithm, we will check concave

nature of the profit function and finding the solution which is optimum also doing the sensitivity analysis of decision variables by varying the inventory parameters $-20 \%$ to $20 \%$ only for case- 5 only as shown in figure- 1 and table-1.

Computing the eigen values of the Hessian matrix

$H=\left[\begin{array}{ll}\frac{\partial^{2} T P}{\partial T^{2}} & \frac{\partial^{2} T P}{\partial T p} \\ \frac{\partial^{2} T P}{\partial p T} & \frac{\partial^{2} T P}{\partial p^{2}}\end{array}\right]=\left[\begin{array}{cc}-26943.7594 & 0.6400 \\ 0.6400 & -0.0014\end{array}\right]$

The two eigen values are

$\lambda_{1}=-26943.7594<0, \quad \lambda_{2}=-0.0014<0$

Therefore, the two eigen values of Hessian matrix are negative. So, the profit function is concave down in nature as shown in the figure-1, which demonstrates the local maximum of the total profit function.

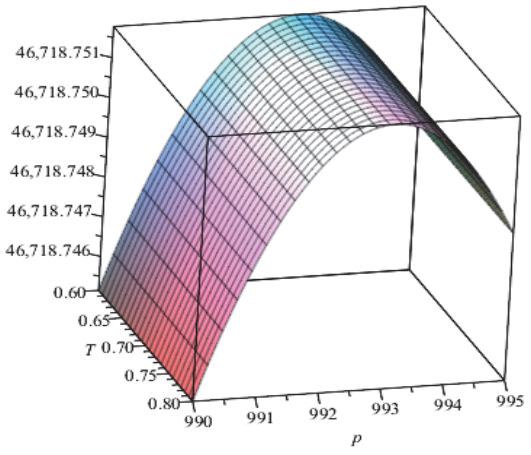

Fig. 1. Concavity of total profit function (case-5)

\subsection{Sensitivity analysis on the optimal inventory policy:}

In this part, the sensitivity analysis of the decision variables with respect to various inventory parameters is carried out. As, the maximum profit gain is in case-5; So, by utilizing the values of inventory parameters of example-5; The table- 1 demonstrates the values of decision variables on varying the various inventory parameters from case-5 in the range $-20 \%$ to $20 \%$. From table- 1 , the following observations are extracted;

(a) Sensitivity analysis of basic market scale demand $(a)$ :

As the product starts deteriorating the firm tends to sell the products rapidly therefore showing the decrement in replenishment cycle length and selling price resulting in increment in profit margin for the firm with increased optimal quantity.

(b) Sensitivity analysis of linear rate of change of demand (b):

By increasing the selling price of deteriorating items initially; the cycle length becomes lengthier with total profit increment and optimal quantity increases.

(c) Sensitivity analysis of quadratic rate of change of demand (c):

With the decrement in replenishment cycle as well as selling price of deteriorating items, the total profit decreases with less optimal ordered quantity. 
(d) Sensitivity analysis of holding cost $(h)$ :

The replenishment cycle, optimal quantity remains constant with a minor increment in selling price and minor decrement in total profit with respect to the variation of holding cost.

(e) Sensitivity analysis of unit purchasing cost $(C)$ :

With an increment in selling price, decrement in ordered quantity and lengthier cycle length; the total profit decreases, with respect to variation of unit purchasing cost.

(f) Sensitivity analysis of cash discount rate offered by the supplier $\left(d_{1}\right)$ :

By a decrement in selling price and lengthening the replenishment cycle length and increasing the ordering quantity of deteriorating items increases the total profit.

(g) Sensitivity analysis of cash discount rate offered by the retailer $\left(d_{2}\right)$ :

With respect to the variation of cash discount rate offered by the retailer, each decision variable remains constant, along with constant total profit.

(h) Sensitivity analysis of fixed ordering $\operatorname{cost}(A)$ :

With the variation of fixed ordering cost there is an increment seen in selling price, replenishment cycle length and ordered quantity of deteriorating items resulting in decrement in the total profit decreases.

(a) Sensitivity analysis of constant deterioration rate $(\theta)$ :

With the variation of deterioration rate, there is an increment selling price, optimal order quantity and lengthening of cycle time resulting in lowering the total profit margin.

(b) Sensitivity analysis of annual interest charged $\left(I_{c}\right)$ :

The total profit declines with the variation in annual interest charged, shortening cycle time by increasing selling price, decrement in optimal ordering quantity.

(c) Sensitivity analysis of annual interest earned $\left(I_{e}\right)$ :

With the variation of annual interest earned, along with total profit, each decision variable shows constant values. So, there is no noticeable variation in total profit with respect to variation in $I_{e}$.

(d) Sensitivity analysis of markup for selling price $(\eta)$ :

With respect to variation in $\eta$, by increasing the selling price the total profit varies by increasing optimal order quantity and varying the replenishment cycle length. So, all the decision variables fluctuates highly with respect to $\eta$.

(e) Sensitivity analysis of the quantity at which the supplier provides the cash discount rate $d_{1}$ to the retailer $\left(Q_{1}\right)$.

With the variation of the quantity at which the supplier provides the cash discount rate $d_{1}$ to the retailer, along with total profit, each decision variable shows constant values. So, there is no significant variation in total profit with respect to variation in $Q_{1}$.

(a) Sensitivity analysis of $i^{\text {th }}$ permissible delay period $\left(M_{i}\right), i=1,2,3$ :

With the variation of the permissible delay period $M_{i}, i=1,2,3$ along with total profit, each decision variable shows constant values. So, there is no remarkable variation in total profit with respect to variation in $M_{i}, i=1,2,3$. 
Table 1

Sensitivity analysis of decision variables w. r. to various inventory parameters (Case-5)

\begin{tabular}{|c|c|c|c|c|c|c|}
\hline \multirow{2}{*}{$\begin{array}{l}\text { Inventory } \\
\text { Parameters }\end{array}$} & \multirow{2}{*}{$\begin{array}{l}\text { Decision } \\
\text { Variables }\end{array}$} & \multicolumn{5}{|c|}{ Percentage variation of Decision Variables } \\
\hline & & $-20 \%$ & $-10 \%$ & 0 & $10 \%$ & $20 \%$ \\
\hline \multirow{4}{*}{$a$} & $T$ & 0.7353 & 0.7343 & 0.7335 & 0.7329 & 0.7324 \\
\hline & $p$ & 993.7551 & 993.3358 & 992.999 & 992.7224 & 992.4911 \\
\hline & $Q^{*}$ & 29 & 33 & 37 & 40 & 44 \\
\hline & $T P$ & 37347.7705 & 42033.2521 & 46718.7517 & 51404.2643 & 56089.7868 \\
\hline \multirow{4}{*}{$b$} & $T$ & 0.5877 & 0.6603 & 0.7335 & 0.8071 & 0.8809 \\
\hline & $p$ & 932.1115 & 962.4392 & 992.9990 & 1023.7063 & 1054.5091 \\
\hline & $Q^{*}$ & 29 & 33 & 37 & 40 & 45 \\
\hline & $T P$ & 44109.15 & 45342.4367 & 46718.7517 & 48238.7409 & 49902.7409 \\
\hline \multirow{4}{*}{$c$} & $T$ & 0.9146 & 0.8139 & 0.7335 & 0.6679 & 0.6134 \\
\hline & $p$ & 1068.5265 & 1026.5262 & 992.9990 & 965.6296 & 942.8753 \\
\hline & $Q^{*}$ & 44 & 40 & 37 & 34 & 31 \\
\hline & $T P$ & 48484.9078 & 47505.2235 & 46718.7517 & 46072.8360 & 45532.3616 \\
\hline \multirow{4}{*}{$h$} & $T$ & 0.7335 & 0.7335 & 0.7335 & 0.7335 & 0.7335 \\
\hline & $p$ & 992.9730 & 992.9860 & 992.9990 & 993.012 & 993.0249 \\
\hline & $Q^{*}$ & 37 & 37 & 37 & 37 & 37 \\
\hline & $T P$ & 46718.7893 & 46718.7705 & 46718.7517 & 46718.7330 & 46718.7142 \\
\hline \multirow{4}{*}{$C$} & $T$ & 0.7335 & 0.7335 & 0.7335 & 0.7336 & 0.7336 \\
\hline & $p$ & 794.4089 & 893.7034 & 992.9990 & 1092.2954 & 1191.5928 \\
\hline & $Q^{*}$ & 46 & 41 & 37 & 33 & 30 \\
\hline & $T P$ & 47033.4189 & 46867.0653 & 46718.7517 & 46584.9871 & 46463.2018 \\
\hline \multirow{4}{*}{$d_{1}$} & $T$ & 0.7328 & 0.7331 & 0.7335 & 0.7340 & 0.7344 \\
\hline & $p$ & 1012.1555 & 1002.5479 & 992.9990 & 983.5115 & 974.0884 \\
\hline & $Q^{*}$ & 36 & 36 & 37 & 37 & 37 \\
\hline & $T P$ & 46691.40452 & 46705.0501 & 46718.7517 & 46732.5047 & 46746.3043 \\
\hline \multirow{4}{*}{$d_{2}$} & $T$ & 0.7335 & 0.7335 & 0.7335 & 0.7335 & 0.7335 \\
\hline & $p$ & 992.9990 & 992.9990 & 992.9990 & 992.9990 & 992.9990 \\
\hline & $Q^{*}$ & 37 & 37 & 37 & 37 & 37 \\
\hline & $T P$ & 46718.7517 & 46718.7517 & 46718.7517 & 46718.7517 & 46718.7517 \\
\hline \multirow{4}{*}{$A$} & $T$ & 0.7321 & 0.7328 & 0.7335 & 0.7342 & 0.7349 \\
\hline & $p$ & 992.3892 & 992.6946 & 992.9990 & 993.3022 & 993.6044 \\
\hline & $Q^{*}$ & 36 & 37 & 37 & 37 & 37 \\
\hline & $T P$ & 46746.0408 & 46732.3897 & 46718.7517 & 46705.1266 & 46691.5144 \\
\hline \multirow{4}{*}{$\theta$} & $T$ & 0.6895 & 0.7236 & 0.7335 & 0.7373 & 0.7388 \\
\hline & $p$ & 679.1235 & 896.6790 & 992.9990 & 1035.8711 & 1053.4845 \\
\hline & $Q^{*}$ & -5880 & -1571.4286 & 37 & 805 & 1202 \\
\hline & $T P$ & 47202.0946 & 46854.9085 & 46718.7517 & 46661.5194 & 46638.5790 \\
\hline \multirow{4}{*}{$I_{c}$} & $T$ & 0.7351 & 0.7343 & 0.7335 & 0.7328 & 0.7321 \\
\hline & $p$ & 965.4635 & 979.2423 & 992.9990 & 1006.7344 & 1020.4494 \\
\hline & $Q^{*}$ & 38 & 37 & 37 & 36 & 35 \\
\hline & $T P$ & 46759.2143 & 46738.8252 & 46718.7517 & 46698.9839 & 46679.5122 \\
\hline & $T$ & 0.7335 & 0.7335 & 0.7335 & 0.7335 & 0.7335 \\
\hline & $p$ & 992.9990 & 992.9990 & 992.9990 & 992.9990 & 992.9990 \\
\hline$I_{e}$ & $Q^{*}$ & 37 & 37 & 37 & 37 & 37 \\
\hline & $T P$ & 46718.7517 & 46718.7517 & 46718.7517 & 46718.7517 & 46718.7517 \\
\hline & $T$ & 2.8777 & 2.9063 & 0.7335 & 0.6123 & 0.6813 \\
\hline$\eta$ & $p$ & 40.5503 & 41.0634 & 992.9990 & 160.4202 & 302.6650 \\
\hline & $Q^{*}$ & -3979 & -2992.466 & 37 & 81 & 76 \\
\hline & $T P$ & -43279.0901 & -29548.3765 & 46718.7517 & 17039.0725 & 29696.5364 \\
\hline & $T$ & 0.7335 & 0.7335 & 0.7335 & 0.7335 & 0.7335 \\
\hline & $p$ & 992.9990 & 992.9990 & 992.9990 & 992.9990 & 992.9990 \\
\hline$Q_{1}$ & $Q^{*}$ & 37 & 37 & 37 & 37 & 37 \\
\hline & $T P$ & 46718.7517 & 46718.7517 & 46718.7517 & 46718.7517 & 46718.7517 \\
\hline & $T$ & 0.7335 & 0.7335 & 0.7335 & 0.7335 & 0.7335 \\
\hline & $p$ & 992.9990 & 992.9990 & 992.9990 & 992.9990 & 992.9990 \\
\hline$M_{0}$ & $Q^{*}$ & 37 & 37 & 37 & 37 & 37 \\
\hline & $T P$ & 46718.7517 & 46718.7517 & 46718.7517 & 46718.7517 & 46718.7517 \\
\hline & $T$ & 0.7335 & 0.7335 & 0.7335 & 0.7335 & 0.7335 \\
\hline & $p$ & 992.9990 & 992.9990 & 992.9990 & 992.9990 & 992.9990 \\
\hline$M_{1}$ & $Q^{*}$ & 37 & 37 & 37 & 37 & 37 \\
\hline & $T P$ & 46718.7517 & 46718.7517 & 46718.7517 & 46718.7517 & 46718.7517 \\
\hline & $T$ & 0.7335 & 0.7335 & 0.7335 & 0.7335 & 0.7335 \\
\hline & $p$ & 992.9990 & 992.9990 & 992.9990 & 992.9990 & 992.9990 \\
\hline$M_{2}$ & $Q^{*}$ & 37 & 37 & 37 & 37 & 37 \\
\hline & $T P$ & 46718.7517 & 46718.7517 & 46718.7517 & 46718.7517 & 46718.7517 \\
\hline
\end{tabular}

\section{Conclusion}

In this article inventory model for deteriorating items are proposed depending upon various time zones different cases have been discussed which maximizes the total profit by synchronizing various concepts like, two levels of trade credit, cash discount and quantity discount for deteriorating items with market demand depending on selling price and time and to construct a unique inventory model when the cash discount for the retailer depends on the ordering quantity and cash discount for the customer depends on the time when customer buys item is considered. The customer's demand is 3expressed as a function of time and price, which is appropriate for the products for which demand increases initially and after 
sometime it starts to decrease. The variable demand with combining all above stated concepts for deteriorating products makes this article a unique one. Finally, in order to validate the derived models, numerical examples along with sensitivity analysis are undertaken, which extracts some fruitful managerial insights. It is observed from demonstrated examples that the maximum profit is gained in

case-5, when $\frac{Q_{1}}{\int_{0}^{T} D t d t} \leq T$, where $Q>Q_{1}$. Also, basic market scale demand, linear rate of change of

demand, cash discount rate offered by the supplier increases the total profit while the quadratic rate of change of demand, holding cost, purchasing cost, ordering cost, deterioration rate, annual interest charged declines the total profit. So, it is advisable to take steps in order to increase basic demand rate, linear rate of change of demand by offering trade credit periods. Also, discount rate offered by the supplier is encouraged. Also, deterioration rate can be decreased by inserting preservation technology investment scheme. It is suggested to encourage in service and advertising effort investments without shortages, in order to raise the profit margin of the firm. Instead of single product, a multi-product situation with common resource constraints can be stretched in future work.

\section{References}

Abad, P. L., and Jaggi, C. K. (2003). A joint approach for setting unit price and the length of the credit period for a seller when end demand is price sensitive. International Journal of Production Economics, 83(2), 115-122.

Aggarwal S. P., and Jaggi C. K. (1995). Ordering policies of deteriorating items under permissible delay in payments. Journal of the Operational Research Society, 46(5), 658-662.

Arcelus F.J., Shah N. H., and Srinivasan G. (2003). Retailer's pricing, credit and inventory policies for deteriorating items in response to temporary price/credit incentives. International Journal of Production Economic, 81(1), 153-162.

Bose, S., Goswami, A. and Chaudhuri, K.S. (1995). An EOQ model for deteriorating items with linear time dependent demand rate and shortages under inflation and time discounting. Journal of the Operational Research Society, 46(6), 771-782.

Chang, C. T. (2004). An EOQ model with deteriorating items under inflation when supplier credits linked to order quantity. International Journal of Production Economics, 88(3), 307-316.

Chang, C. T., and Teng, J.T. (2004). Retailer's optimal ordering policy under supplier credits. Mathematical Methods of Operation Research, 60(3), 471-483.

Chung, K. J., and Liao, J. J. (2004). Lot-sizing decisions under trade credit depending on the ordering quantity. Computer \& Operations Research, 31(6), 909-928.

Chung, K. J., (2010). The complete proof on the optimal ordering policy under cash discount and trade credit. International Journal of System Science, 41(4), 467-475.

Chung, K.J., and Ting, P.S. (1993). A heuristic for replenishment of deteriorating items with a linear trend in demand. Journal of the Operational Research Society, 44(12), 1235-1241.

Chung, K.J., and Ting, P.S. (1994). On replenishment schedule for deteriorating items with time proportional demand. Production Planning and Control, 5(4), 392-396.

Chung, K. J., Liao J. J., Ting P. S., Lin S. D., and Srivastava H. M., (2017). A unified presentation of inventory models under quantity discounts, trade credits and cash discounts in the supply chain management, Revista de la Real Academia de Ciencias Exactas, Fisicas y Naturales. Serie A. Mathematicas, 29, 1-30.

Dolan, R. J. (1987). Quantity discounts: managerial issues and research opportunities. Marketing Science, 6(1), 1-22.

Goyal S. K., (1985). Economic order quantity under conditions of permissible delay in payments. Journal of the Operational Research Society, 36(4), 335-338.

Hariga, M. (1995). An EOQ model for deteriorating items with shortages and time-varying demand. Journal of the Operational Research Society. 46(4), 398-404.

Haley, C. W. and Higgins, R. C. (1973). Inventory policy and trade credit financing. Management Science. 20(4), 464-471.

Hill, N., Riener, K. (1979). Determining the cash discount in the firm's credit policy. Financial Management, 8(4), 68-73.

Ho, C. H.I., Ouyang, L.Y., Su, C. H. (2008). Optimal pricing, shipment and payment policy for an integrated supplierbuyer inventory model with two-part trade credit. European Journal of Operational Research, 187(2), 496-510.

Huang, Y. F. (2003). Optimal retailer's ordering policies in the EOQ model under trade credit financing. Journal of Operational Research Society, 54(9), 1011-1015.

Huang, Y. F. (2005). Buyer's optimal ordering policy and payment policy under supplier credit. International Journal of System Sciences, 36(13), 801-807.

Huang, Y. F. (2006). An inventory model under two-levels of trade credit and limited storage space derived without derivatives. Applied Mathematical Modelling, 30(5), 418-436.

Huang, Y. F., and Chung, K. J. (2003). Optimal replenishment and payment policies in the EOQ model under cash discount and trade credit. Asia Pacific Journal of Operational Research, 20(2), 177-190. 
Huang, Y. F. and Hsu, K. H. (2007). An EOQ model with non-instantaneous receipt under supplier credits. Journal of Operational Research Society of Japan, 50(1), 1-13.

Jamal, A. M. M., Sarker B. R. and Wang, S. (2000). Optimal payment time for a retailer under permitted delay of payment by the wholesaler. International Journal of Production Economics 66(1), 59-66.

Kingsman B. G. (1983). The effect of payment rules on ordering and stocking in purchasing, Journal of the Operational Research Society, 34(11), 1085-1098.

Kreng V. B. and Tan S. J. (2010). The optimal replenishment decisions under two levels of trade credit policy depending on the order quantity. Expert Systems with Applications 37(7), 5514-5522.

Lee, Y.P. and Dye, C.Y. (2012). An inventory model for deteriorating items under stock-dependent demand and controllable deterioration rate. Computers and Industrial Engineering, 63(2), 474-482.

Lin, C., Tan, B. and Lee, W.C. (2000). An EOQ model for deteriorating items with time-varying demand and shortages. International Journal of Systems Science, 31(3), 394-400.

Lin, Y. J., Ouyang, L.Y. and Dang, Y. F. (2012). A joint optimal ordering and delivery policy for an integrated supplierretailer inventory model with trade credit and defective items. Applied Mathematics and Computation, 218(14), 74987514.

Mahata, G. C. (2012), An EPQ-based inventory model for exponentially deteriorating items under retailer partial trade credit policy in supply chain. Expert Systems with Applications, 39(3), 3537-3550.

Mahata, G. C. and Goswami A. (2006). Production lot-size model with fuzzy production rate and fuzzy demand rate for deteriorating item under permissible delay in payments. Opsearch 43(4), 358-375.

Mahata, G. C. and Goswami A. (2007). An EOQ model for deteriorating items under trade credit financing in the fuzzy sense. Production Planning and Control, 18(8), 681-692.

Mahata, G. C. and Mahata P. (2011). Analysis of a fuzzy economic order quantity model for deteriorating items under retailer partial trade credit financing in a supply chain. Mathematical and Computer Modelling, 53(9-10), 1621-1636.

Mehta, N.J. and Shah, N.H. (2003). An inventory model for deteriorating items with exponentially increasing demand shortages under inflation and time discounting. Investigacao Operacional, 23(1), 103-111.

Mehta, N.J., and Shah, N.H. (2004). An inventory model for deteriorating items with exponentially decreasing demand shortages under inflation and time discounting. Industrial Engineering Journal, 33(4), 19-23.

Min, J. and Zhou, Y. W. (2009). A perishable inventory model under stock-dependent selling rate and shortage-dependent partial backlogging with capacity constraint, International Journal of Systems Science, 40(1), 33-44.

Mishra V. K., Singh L. S., Kumar R. (2013). An inventory model for deteriorating items with time-dependent demand and time varying holding cost under partial backlogging. Journal of Industrial Engineering International, 9(4), 1-5.

Ouyang, L.Y., Teng, J.T., Chuang, K.W. and Chuang, B.R. (2005). Optimal inventory policy with non-instantaneous receipt under trade credit. International Journal of Production Economics, 98(3), 290-300.

Sana, S.S., Chaudhuri, K.S. (2008). A deterministic EOQ model with delays in payments and price-discount offers. European Journal of Operation Research, 184(2), 509-533.

Shah N. H., Shah Y. K. (1998). A discrete-in-time probabilistic inventory model for deteriorating items under conditions of permissible delay in payments. International Journal of Systems Science, 29(2), 121-126.

Shah, N.H., Gor, A.S., and Jhaveri, C. (2009). Integrated optimal solution for variable deteriorating inventory system of vendor-buyer when demand is quadratic. Canadian Journal of Pure and Applied Sciences, 3(1), 713-717.

Shah, N.H., and Shah, B.J. (2014). EPQ model for time-declining demand with imperfect production process under inflationary conditions and reliability. International Journal of Operations Research, 11(3), 91-99.

Silver, E.A. and Meal, H.C. (1969). A simple modification of the EOQ for the case of a varying demand rate. Production and Inventory Management, 10(4), 52-65.

Silver, E.A. (1979). A simple inventory replenishment decision rule for a linear trend in demand. Journal of the Operational Research Society, 30(1), 71-75.

Teng, J. T., Chang, C. T., and Goyal, S. K. (2005). Optimal pricing and ordering policy under permissible delay in payments. International Journal of Production Economics, 97(2), 121-129.

Yang, H. L., Teng, J.T., and Chern, M. S. (2010). An inventory model under inflation for deteriorating items with stockdependent consumption rate and partial backlogging shortages. International Journal of Production Economics, 123(1), 8-19.

Yang, C. T. (2010). The optimal order and payment policies for deteriorating items in discount cash flows analysis under the alternatives of conditionally permissible delay in payments and cash discount. TOP, 18(2), 429-443.

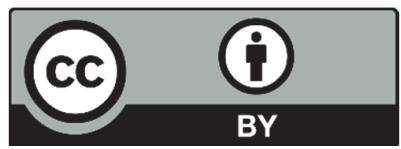

(C) 2019 by the authors; licensee Growing Science, Canada. This is an open access article distributed under the terms and conditions of the Creative Commons Attribution (CC-BY) license (http://creativecommons.org/licenses/by/4.0/). 